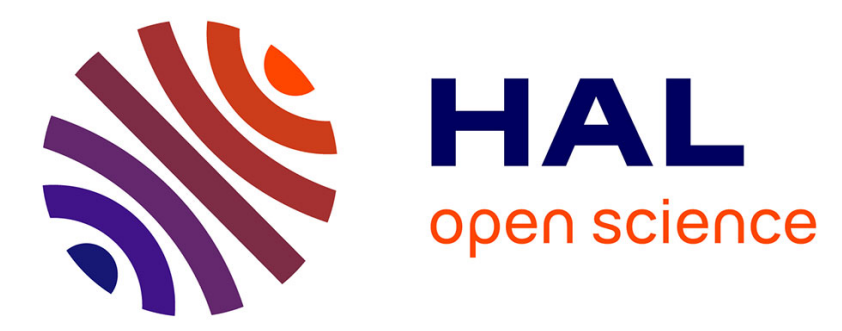

\title{
Effect of thermal treatment conditions on the properties of onion-like-carbon based polymer composite
}

J. Macutkevic, D. Seliuta, G. Valusis, J. Banys, S. Hens, V. Borjanovic, V. Kuznetsov, O. Shenderova

\section{- To cite this version:}

J. Macutkevic, D. Seliuta, G. Valusis, J. Banys, S. Hens, et al.. Effect of thermal treatment conditions on the properties of onion-like-carbon based polymer composite. Composites Science and Technology, 2010, 70 (16), pp.2298. 10.1016/j.compscitech.2010.09.008 . hal-00696569

\section{HAL Id: hal-00696569 \\ https://hal.science/hal-00696569}

Submitted on 12 May 2012

HAL is a multi-disciplinary open access archive for the deposit and dissemination of scientific research documents, whether they are published or not. The documents may come from teaching and research institutions in France or abroad, or from public or private research centers.
L'archive ouverte pluridisciplinaire HAL, est destinée au dépôt et à la diffusion de documents scientifiques de niveau recherche, publiés ou non, émanant des établissements d'enseignement et de recherche français ou étrangers, des laboratoires publics ou privés. 


\section{Accepted Manuscript}

Effect of thermal treatment conditions on the properties of onion-like-carbon based polymer composite

J. Macutkevic, D. Seliuta, G. Valusis, J. Banys, S. Hens, V. Borjanovic, V.

Kuznetsov, O. Shenderova

PII:

S0266-3538(10)00353-2

DOI:

10.1016/j.compscitech.2010.09.008

Reference:

CSTE 4811

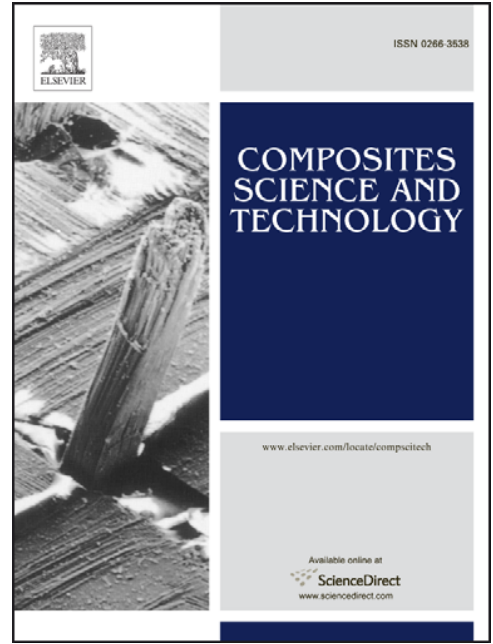

To appear in:

Composites Science and Technology

Received Date:

1 April 2010

Revised Date:

8 September 2010

Accepted Date:

13 September 2010

Please cite this article as: Macutkevic, J., Seliuta, D., Valusis, G., Banys, J., Hens, S., Borjanovic, V., Kuznetsov, V., Shenderova, O., Effect of thermal treatment conditions on the properties of onion-like-carbon based polymer composite, Composites Science and Technology (2010), doi: 10.1016/j.compscitech.2010.09.008

This is a PDF file of an unedited manuscript that has been accepted for publication. As a service to our customers we are providing this early version of the manuscript. The manuscript will undergo copyediting, typesetting, and review of the resulting proof before it is published in its final form. Please note that during the production process errors may be discovered which could affect the content, and all legal disclaimers that apply to the journal pertain. 


\title{
Effect of thermal treatment conditions on the properties of onion-like-carbon
}

\section{based polymer composite}

\author{
J. Macutkevic ${ }^{1 *}$, D. Seliuta ${ }^{1}$, G. Valusis ${ }^{1}$, J. Banys ${ }^{2}$, S. Hens $^{3}$, V. Borjanovic ${ }^{3}$, V. Kuznetsov ${ }^{4}$, \\ O. Shenderova ${ }^{3}$
}

${ }^{1}$ Centre of Physical and Technological Sciences, Semiconductor Physics Institute, A. Gostauto g. 11, LT-01108 Vilnius, Lithuania, Phone: + 3705212 4539, Fax: +370 526271 23. E-mail: jan@pfi.lt

${ }^{2}$ University of Vilnius, Sauletekio al. 9, LT-00122 Vilnius, Lithuania, tel. +370-5-2687015, Fax: +370-5-2687009, E-mail: juras.banys@ff.vu.lt;

${ }^{3}$ International Technology Center, Raleigh, NC 27715, USA, Phone: +1 (919)-881-0250(-226), Fax: +1 (919)-881-0440, E-mail: oshenderova@itc-inc.org

${ }^{4}$ Boreskov Institute of Catalysis SB RAS, Lavrentiev Ave. 5, Novosibirsk, 630090, Russia, Phone: +7-3833-308765, Fax: +7-3833-308056, E-mail: kuznet@ catalysis.nsk.su

\section{ABSTRACT}

Dielectric properties of onion like carbon (OLC) and polyurethane composite prepared using different procedures were investigated in the frequency range up to $1 \mathrm{MHz}$. We show that broadband dielectric spectroscopy is powerful tool to determine technological fingerprints in the studied materials. It is demonstrated that cured samples annealed at temperature close to the melting point $(450 \mathrm{~K})$ exhibit substantially higher dielectric permittivity and electrical conductivity in comparison with untreated samples. With the increase of temperature of an untreated sample, its dielectric permittivity, electric conductivity and critical frequency increase, while MaxwellWagner mean relaxation time and aggregate sizes of OLC decreases. Annealing of the composite at temperature close to the melting temperature produce sample with more homogeneous distribution of OLC. The temperature dependence of conductivity of the homogeneous sample is mainly caused by a weak positive temperature coefficient effect.

Keywords A. Nano composites, B. Transport properties, E. Annealing, E. Heat treatment, Onionlike Carbon.

\section{Introduction}

Electrically percolative polymer-based composites have been attracting much attention because of their potential applications such as electroactive materials, sensitive materials, and electromagnetic coatings. Owing to the advanced electrical, thermal, and mechanical properties, various carbon nanoparticles like carbon nanotubes or carbon black have been widely studied and often used as nanofillers in the past few years. The main advantage of carbon nanotubes versus other carbon nanofillers is their extremely low percolation threshold [1]. Nevertheless, the percolation threshold in carbon nanotubes based composites dependents on many factors such as polymer type and dispersion method [2]. The onion-like carbons (OLCs), consisting of stable defected multishell fullerenes, exhibit high conductivity similar to carbon nanotubes [3]. The OLC have a rare structure allowing for hierarchical assembly of conductive structural units and high concentration of electrically active defects, being able to absorb a wideband of electromagnetic radiation [4].

\footnotetext{
${ }^{*}$ Corresponding author. Fax: +370 526271 23. E-mail address: jan@pfi.lt
} 
Nevertheless, the first investigations of OLC based composites have shown low dielectric permittivity and electrical conductivity similar to the pure polymer matrix parameters [5-7]. It was observed, however, that the dielectric permittivity and electrical conductivity drastically increase in onion-like-based composite approaching the percolation point [8]. It is interesting to note that in the OLC polyurethane (PU) composite, the percolation point of a $10 \%$ volume fraction is estimated [8], and this is lower than a prediction from an effective medium approximation for the inclusions with a spherical shape (the percolation threshold for spherical inclusions is close to $1 / 3$ volume fraction [9]). Carbon black topology is similar to OLC. For carbon black, the percolation threshold depends on the preparation technology and can be similar to carbon nanotubes, i.e., it can be also very low [10]. Therefore, for OLC applications it is very important to find optimal technological ways to further reduce the percolation threshold [8] and to study the effect of technological procedures on the electrical/dielectrical properties of the structures.

In this paper, we therefore, investigate an influence of preparation conditions on OLC/PU dielectric properties in order to find a most favorable technology for producing coatings with a low percolation threshold. In more detail, we explore the role of heating of the samples during mixing of OLC and PU solution as well as annealing effect of the cured films.

\section{Sample preparation technology and experimental part}

The OLC material was produced by annealing of detonation nanodiamond powder in vacuum at $1800 \mathrm{~K}$, as it described by Kuznetsov et al. [3]. Nanodiamonds were purchased from New Technologies, Chelyabinsk. Average primary particle size of DND was $4 \mathrm{~nm}$ and the average volumetric aggregate size was $120 \mathrm{~nm}$. To achieve fully transformed DND into OLC, DNDs were heated in vacuum $10^{-4}$ torr at $1800 \mathrm{~K}$ for $2 \mathrm{~h}$. Size of primary OLC particles is around 6-7 nm, while average aggregate size is $130 \mathrm{~nm}$ for OLC dispersed in $N$-methylpyrrolidone solvent as measured by dynamic light scattering technique.

Samples of OLC were mixed with commercial formulation of oil-based polyurethane "Minwax clear satin" containing 60\% of volatile compounds. All samples contained $15 \mathrm{wt} . \%$ of OLC. Six samples were prepared under different thermal treatment conditions (more detailed information can be found in Table 1). First, after manual mixing with the OLC powder, the polymer suspension was magnetically stirred at $400 \mathrm{rpm}$ during $24 \mathrm{hrs}$ at $50{ }^{\circ} \mathrm{C}$. Then, before casting a suspension, samples 2 and 3 were additionally heated at $70{ }^{\circ} \mathrm{C}$ and $90{ }^{\circ} \mathrm{C}$, correspondingly, on a hot plate with a purpose to improve uniformity in distribution of OLC in a polymer solution with a lower viscosity. Then suspensions were casted on a Teflon substrate and dried at ambient conditions at $45^{\circ} \mathrm{C}$ overnight. Half of the dried samples ("b" series) were additionally annealed at $150{ }^{\circ} \mathrm{C}$ during $1 \mathrm{hr}$ under pressure in an oven. A motivation for this treatment originated from our observation that after testing of dielectric properties of the samples at high temperatures (for example, $450 \mathrm{~K}$ ), dielectric constants and conductivities of the samples, when cooled to the room temperature, were increased. Thus, we introduced an annealing stage during sample preparation. Thickness of OLC/PU films varied between 250 and $700 \mu \mathrm{m}$. Distribution of OLC in PU matrix was characterized by scanning electron microscope SEM Zeiss Supra 25.

To characterize the samples we have employed broadband dielectric spectroscopy. This technique was already proved to be powerful tool to characterize these materials $[5,6,8]$. The complex dielectric permittivity $\varepsilon^{*}=\mathcal{E}^{\prime}-i \mathcal{E}^{\prime \prime}$ was measured by a capacitance bridge HP4284A in the frequency range $20 \mathrm{~Hz}-1 \mathrm{MHz}$. Measurements have been performed on cooling and heating at a rate of about $0.5 \mathrm{~K} / \mathrm{min}$. Each measurement started from heating, and after reaching $450 \mathrm{~K}$, the sample was kept at this temperature for $\sim 0.5 \mathrm{hr}$, and then the samples were cooled down to room temperature. 


\section{Results and discussion}

Figure1 illustrates SEM images of the top view of the samples $3 \mathrm{a}$ and $3 \mathrm{~b}$ at the same magnification. As can be seen from the images, OLCs are uniformly distributed within the matrix and OLC aggregate sizes are smaller in the annealed sample $3 \mathrm{~b}$.

The frequency dependence of dielectric permittivity $\mathcal{E}^{\prime}$ and electrical conductivity $\sigma^{\prime}$ at room temperature for composites prepared under different conditions with OLC concentration of $15 \%$ is shown in Fig. 2. It can be seen that both dielectric permittivity $\mathcal{E}^{\prime}$ and electrical conductivity $\sigma^{\prime}$ is strongly influenced by preparation conditions. In particular, it is more pronounced at low frequencies. All annealed samples $(1 \mathrm{~b}-3 \mathrm{~b})$ exhibit higher electrical conductivity $\sigma^{\prime}$ and dielectric permittivity $\mathcal{E}^{\prime}$ in comparison with not treated samples in the frequency range up to $1 \mathrm{MHz}$. The highest electrical conductivity $\sigma^{\prime}$ and dielectric permittivity $\mathcal{E}^{\prime}$ are observed in $3 \mathrm{~b}$ sample. The increasing of dielectric permittivity $\mathcal{E}^{\prime}$ at low frequencies (below $300 \mathrm{~Hz}$ ) in the annealed sample is obviously caused by Maxwell-Wagner relaxation [11]. In order to explain an effect of annealing on the dielectric properties, measurements of dielectric properties were performed under heating at different frequencies. These results for the most representative samples $3 \mathrm{a}$ (not annealed) and $3 \mathrm{~b}$ (annealed) are shown in Fig. 3. As one can see, the dielectric permittivity $\mathcal{E}^{\prime}$ and electrical conductivity $\sigma^{\prime}$ increase on heating in both annealed and untreated samples, however, in the untreated sample the increase is more pronounced. It is worth noting that more pronounced changes of dielectric properties take place at low frequencies. The electrical conductivity also exhibits a kink in sample $3 \mathrm{~b}$ at nearly $380 \mathrm{~K}$. It is probably associated with the fact that polymer molecules can move more freely at this temperature, because conductivity and dielectric permittivity of pure polyurethane also exhibit kinks close to this temperature. Usually, such temperature is associated with alfa (glass) transition in polymers [12]. To get deeper insight into processes, frequency dependence of dielectric permittivity $\varepsilon^{\prime}$ and electrical conductivity $\sigma^{\prime}$ on the heating of composites $3 \mathrm{a}$ and $3 \mathrm{~b}$ are plotted and presented in Fig. 4a and Fig. 4b, respectively. It can be seen that the dielectric permittivity $\mathcal{E}^{\prime}$ measured at room temperature strongly decreases with the frequency, meanwhile electrical conductivity strongly increases with frequency in the untreated sample. Thus, it is not possible to estimate DC conductivity in our frequency range. On further heating of untreated sample frequency-independent (DC) conductivity becomes observable only at low frequencies.

To analyze the data, we have used an approach in which the frequency dependence of $\sigma$ can be fitted according to the Almond-West type power law with a single exponent:

$$
\sigma=\sigma_{D C}+A \omega^{s},
$$

where $\sigma_{D C}$ stands for the DC conductivity and $A \omega^{s}$ is the AC contribution. It is evident from Fig. 4a and $4 \mathrm{~b}$ that the DC conductivity $\sigma_{D C}$ coincides with conductivity at $129 \mathrm{~Hz}$ in annealed samples (3b) and in untreated sample (3a) at higher temperatures. In the untreated sample the low frequency dielectric dispersion (below $1 \mathrm{kHz}$ ), mentioned above as Maxwell-Wagner relaxation, is strongly temperature-dependent. The Maxwell-Wagner relaxation can be described by Cole-Cole formula [13]:

$$
\varepsilon^{*}=\varepsilon_{\infty}+\frac{\Delta \varepsilon}{1+\left(i \omega \tau_{C C}\right)^{1-\alpha}}
$$

where $0 \leq \alpha \leq 1$ are the parameters of width of Cole-Cole distributions functions, $\tau_{C C}$ is the mean and most probable Cole-Cole relaxation time, $\Delta \varepsilon$ is the dielectric strength, $\varepsilon_{\infty}$ is the high frequency dielectric permittivity. However, in our case the Cole-Cole fit for low frequency dielectric 
dispersion cannot be performed, because the mean relaxation $\tau_{\mathrm{CC}}$ is very long and $1 / \tau_{\mathrm{CC}}$ is substantially below of our low frequency limit. Nevertheless, it is easy to conclude that the mean relaxation $\tau_{\mathrm{CC}}$ decreases on cooling in both annealed and untreated sample. In the Maxwell-Wagner relaxation case, $\tau_{\mathrm{CC}}=\mathrm{RC}$, where $\mathrm{R}$ and $\mathrm{C}$ is the resistance and the capacitance of grains, respectively. The capacitance of OLC aggregate, a sphere with radius $\mathrm{r}$, can be described as $\mathrm{C}=4 \pi \varepsilon_{0} \mathrm{r}$. Therefore, the decrease of the mean Cole-Cole relaxation time $\tau_{\mathrm{CC}}$ is related to the decrease of the mean size (radius) of the OLC aggregate.

From the Almond-West type fit it is possible to calculate critical frequency $f_{c}$, at which $\sigma$ $(\omega)$ deviates from the dc plateau. Experimental value for $f_{c}$, have been defined as the frequency at which the value of conductivity is $10 \%$ higher than the DC conductivity value. The results are plotted in Fig. 5. As can be seen, the critical frequency value $f_{c}$ of untreated samples (2a and 3a) at room temperature is very low, and falls below low frequency limit $(20 \mathrm{~Hz})$ of the equipment used. On heating above $350 \mathrm{~K}$, the critical frequency for these samples strongly increases, but still remains lower in comparison with annealed samples.

To estimate an activation energy the temperature dependence of $\sigma$ at $129 \mathrm{~Hz}$ (DC conductivity) for different OLC samples are presented in Fig. 5. The activation energy $E$ of the conductivity and the conductivity prefactor $\sigma_{0}$ was evaluated using the Arrhenius law:

$$
\sigma_{D C}=\frac{\sigma_{0}}{T} e^{-\frac{E}{k T}}
$$

The obtained parameters are listed in Table 2. It is evident that the activation energy $E$ of the DC conductivity is higher in untreated samples and pure PU than that in annealed samples. The physics behind that can be associated with an electrical transport via electron diffusion through conducting OLC aggregates and (or) tunneling through a nonconductive (at low temperature) polyurethane matrix. The DC conductivity is a result mainly of electron tunneling through nonconductive polyurethane matrix, because no continued network of OLC clusters is observed in the composite (Fig. 1). Knowing that the activation energy $E$ is a potential barrier for the carriers tunneling, it is reasonable that it is lower in more homogeneously annealed samples (Table 2).

The average time $\tau_{f l}$, which a charge carrier needs to travel through the OLC aggregate, is directly proportional to the aggregate size $d$. The biggest OLC size is observed in an untreated sample (Fig. 1), therefore, it is reasonable to assume that:

$$
f_{c} \propto \frac{1}{\tau_{f l}}
$$

For frequencies $f<f_{c}$ charge carriers can travel over different OLC aggregates within one electromagnetic wave period. In contrast, for frequencies above $f_{c}$ the charge carriers can move mainly within a length of one OLC aggregate. Therefore, the critical frequency $f_{c}$ and its temperature dependence reflect the mean OLC aggregate size. Hence, the observed increase in critical frequency $f_{\mathrm{c}}$ above $350 \mathrm{~K}$ manifests that OLC aggregate size is decreased. It can be thus concluded that annealing is a very important treatment for obtaining a homogeneous composite.

It deserves to emphasize that in contrast to heating measurements the temperature dependence of electrical conductivity and dielectric permittivity of both annealed and untreated samples on cooling is very weak (Fig. 6). Pronounced discontinuity between electrical conductivity and dielectric permittivity data on heating and on cooling indicate that the main composite homogenization process happens during isothermal annealing at $450 \mathrm{~K}$. This temperature is close to the melting point of pure polyurethane (melting temperature of pure polyurethane was 
established in additional experiment and found to be $489 \mathrm{~K}$ ). A small increase of electrical conductivity $\sigma$ on cooling in an untreated sample (above temperature $400 \mathrm{~K}$ ) and in an annealed sample obviously is caused by a positive temperature coefficient effect [14]. The effect results from the break of the conductive links due to the thermal expansion of the polymer matrix. Some small decrease of dielectric permittivity $\mathcal{E}^{\prime}$ and electrical conductivity $\sigma$ on cooling is observed in an untreated sample at low temperatures (below $400 \mathrm{~K}$ ). This phenomenon is related to a negative temperature coefficient effect [14], which is caused by residual redistribution OLC aggregate in polymer matrix.

Finally, we have considered the frequency dependence of electrical conductivity $\sigma$ on cooling. To analyze the data Eq. (1) was used. It was found that the critical frequency only slightly increases on cooling as it is seen from Fig. 7. The low-frequency dielectric dispersion (Maxwell-Wagner relaxation) is also almost stable on cooling. Therefore, one can note that the diffusion of OLC aggregates through polyurethane matrix mainly vanishes in cooling measurement and, as a result, a homogeneous composite is obtained.

\section{Conclusion}

The influence of a preparation procedure on dielectric properties of OLC-polyurethane composites was investigated. Two procedures were implemented: (i) mechanical stirring of OLC and PU in a solvent at increased temperature and (ii) annealing of the cured samples. It was concluded that heating of the suspension during mixing of OLC and PU has not so significant effect on the enhancement of the dielectric properties of the composites, as compared to an annealing of the cured sample. Samples annealed close to the melting point $(450 \mathrm{~K})$ exhibit substantially higher dielectric permittivity and electrical conductivity in comparison with an untreated sample. Dielectric permittivity, electric conductivity and critical frequency increased in the untreated sample during heating while Maxwell-Wagner mean relaxation time and average OLC aggregate size decreased. All parameters exhibited an offset close to the alpha (glass) transition temperature $(380 \mathrm{~K})$. Annealing of composites close to the melting temperature results in more homogeneous distribution of OLC. The temperature dependence of conductivity of a homogeneous sample is mainly caused by a weak positive temperature coefficient effect.

\section{Acknowledgements}

This work was partially supported by NATO Collaborative Linkage Grant (Reference No.CBP.EAP.CLG983910). The work was also partially supported by the NATO Science for Peace program (grant SfP 981051). ITC acknowledges the partial support through Air Force Office of Scientific Research under grant N66001-04-1-8933.

\section{References}

[1] J. K. W. Sandler, J. E. Kirk, I. A. Kinloch, M. S. P. Shaffer, A. H. Windle, Ulta-low electrical percolation threshold in carbon-nanotube-epoxy composites, Polymer 44 (2003) 5893.

[2] W. Bauhofer, J. Z. Kovacs, A review and analysis of electrical percolation in carbon nanotube polymer composites, Composites Science and Technology 69 (2009) 1486.

[3] V. L. Kuznetsov, Yu. V. Butenko, A. L. Chuvilin, A. I. Romanenko, and A. V. Okotrub, Electrical resistivity of grafitized ultra-disperse diamond and onion-like carbon, Chem. Phys. Lett. 336, (2001) 397. 
[4] R. Langlet, Ph. Lambin, A. Mayer, P. P. Kuzhir, and S. A. Maksimenko, Dipole polarizability of onion-like carbons and electromagnetic of their composites, Nanotechnology 19 (2008) 115706. [5] J. Macutkevic, D. Seliuta, G. Valusis, J. Banys, P. Kuzhir, S. Maksimenko, V. Kuznetsov, S. Moseenkov, O. Shenderova and Ph. Lambin, Dielectric properties of onion-like carbon based polymer films: experiment and modeling, Solid State Science 11 (2009) 1828.

[6] J. Macutkevic, P. Kuzhir, D. Seliuta, G. Valusis, J. Banys, A. Paddubskaya, D. Bychanok, G. Slepyan, S. Maksimenko, V. Kuznetsov, S. Moseenkov, O. Shenderova, A. Mayer, Ph. Lambin, Dielectric properties of a novel high absorbing onion-like-carbon based polymer composite, Diamond \& related materials 19 (2010) 91.

[7] J. Macutkevic, R. Adomavicius, A. Krotkus, D. Seliuta, G. Valusis, S. Maksimenko, P. Kuzhir, K. Batrakov, V. Kuznetsov, S. Moseenkov, O. Shenderova, A. V. Okotrub, R. Langelet, Ph. Lambin, Terahertz probing of onion-like carbon-PMMA composite films, Diamond \& related materials 17 (2008) 1608.

[8] J. Macutkevic, D. Seliuta, G. Valusis, J. Banys, V. Kuznetsov, S. Moseenkov, O. Shenderova, High dielectric permittivity of percolative composites based on onion-like carbon, App. Phys. Lett. 95, (2009) 112901.

[9] I. Rychetsky, O. Hudak, J. Petzelt, Dielectric properties of microcomposite ferroelectrics, Phase Transitions 67, (1999) 725.

[10] L. J. Adrianse, J. A. Redijk, P. A. A. Teunissen, H. B. Brom, M. A. J. Michels, J. C. M. Brokken-Zijp, High-dilution carbon black/polymer composites: hierarchical percolating network derived from Hz to THz AC conductivity, Phys. Rev. Lett. 78, (1997) 1755.

[11] J. Liu, Ch. Duan, W. N. Mei, R. W. Smith, J. R. Hardy, Dielectric properties and MaxwellWagner relaxation of compounds $\mathrm{ACu}_{3} \mathrm{Ti}_{4} \mathrm{O}_{12}\left(\mathrm{~A}=\mathrm{Ca}, \mathrm{Bi}_{2 / 3}, \mathrm{Y}_{2 / 3}, \mathrm{La}_{2 / 3}\right)$, Journal of Applied Physics 98, (2005) 093703.

[12] C. Alvarez, N. T. Correia, J. J. Moura Ramos, A. C. Fernandes, Glass transition temperature and fragility in a side-chain liquid crystalline polymer: a study by TSDC and DSC, Polymer 41, (2000) 2907.

[13] K. S. Cole and R. Cole, Dispersion and Absorption in Dielectrics I. Alternating Current Characteristics, J. Chem. Phys. 9, (1941) 341.

[14] R. Strümpler, Polymer composite thermistor for temperature and current sensors, Journal of Applied Physics 80, (1996) 6091. 


\section{List of Captions for figures and tables}

Figure 1. SEM images of OLC/PU composites prepared under different conditions: untreated sample $3 \mathrm{a}$ (a) and sample $3 \mathrm{~b}$ annealed at $150^{\circ} \mathrm{C}(\mathrm{b})$.

Figure 2. Frequency dependence of the real parts of complex dielectric permittivity $\varepsilon^{\prime}$ and complex electrical conductivity $\sigma$ prepared under different conditions at room temperature.

Figure 3. Temperature dependence of the real parts of complex dielectric permittivity $\varepsilon^{\prime}$ and complex electrical conductivity $\sigma$ of $3 a(a)$ and $3 b(b)$ sample on heating.

Figure 4. Frequency dependence of the real parts of complex dielectric permittivity $\varepsilon^{\prime}$ and complex electrical conductivity $\sigma$ of $3 a(a)$ and $3 b$ (b) sample on heating.

Figure 5. Temperature dependence of conductivity at $129 \mathrm{~Hz}$ and critical frequency $\mathrm{f}_{\mathrm{c}}$ on heating. Figure 6. Temperature dependence of the real parts of complex dielectric permittivity $\varepsilon^{\prime}$ and complex electrical conductivity $\sigma$ of $3 a(a)$ and $3 b$ (b) sample on cooling.

Figure 7. Temperature dependence of DC conductivity and critical frequency $\mathrm{f}_{\mathrm{c}}$ on cooling.

Table 1. List of investigated OLC/PU composites.

Table 2. Parameters of Arrhenius law obtained from DC conductivity. 


\begin{tabular}{|l|l|l|}
\hline sample & OLC-PU mixing conditions & treatment of a cured sample \\
\hline 1a & 1 day at $50^{\circ} \mathrm{C}$ & untreated \\
\hline 1b & 1 day at $50^{\circ} \mathrm{C}$ & annealing at $150{ }^{\circ} \mathrm{C}$ \\
\hline 2a & 1 day at $50^{\circ} \mathrm{C}+70{ }^{\circ} \mathrm{C} 2 \mathrm{hr}$ & untreated \\
\hline 2b & 1 day at $50^{\circ} \mathrm{C}+70{ }^{\circ} \mathrm{C} 2 \mathrm{hr}$ & annealing at $150{ }^{\circ} \mathrm{C}$ \\
\hline $3 \mathrm{a}$ & 1 day at $50^{\circ} \mathrm{C}+90^{\circ} \mathrm{C} 2 \mathrm{hr}$ & untreated \\
\hline $3 \mathrm{~b}$ & 1 day at $50^{\circ} \mathrm{C}+90^{\circ} \mathrm{C} 2 \mathrm{hr}$ & annealing at $150{ }^{\circ} \mathrm{C}$ \\
\hline
\end{tabular}




\begin{tabular}{|l|l|l|}
\hline sample & $\ln \sigma_{0}, \mathrm{~S} / \mathrm{m}$ & $\mathrm{E} / \mathrm{k}, \mathrm{K}[\mathrm{eV}]$ \\
\hline 1a & 10.94 & $6485.2[0.56]$ \\
\hline 1b & 7.08 & $3668.2[0.32]$ \\
\hline 2a & 11.29 & $7400.4[0.64]$ \\
\hline 2b & 7.11 & $3466.4[0.3]$ \\
\hline 3a & 8.724 & $6086.6[0.52]$ \\
\hline 3b & 8.901 & $3377.2[0.29]$ \\
\hline pure polyurethane & 5.94 & $7284.1[0.63]$ \\
\hline
\end{tabular}




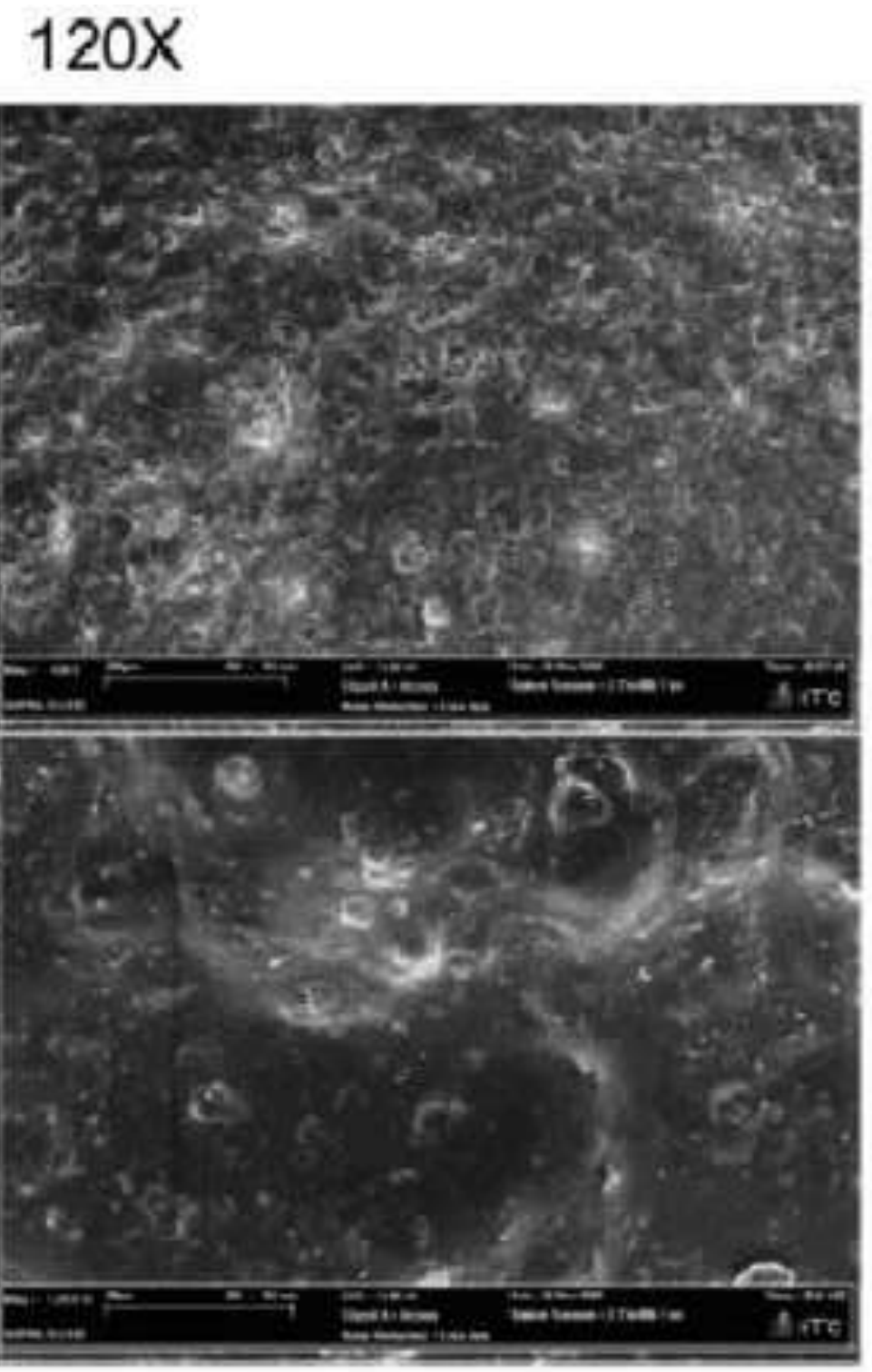

$1,250 X$
$120 x$

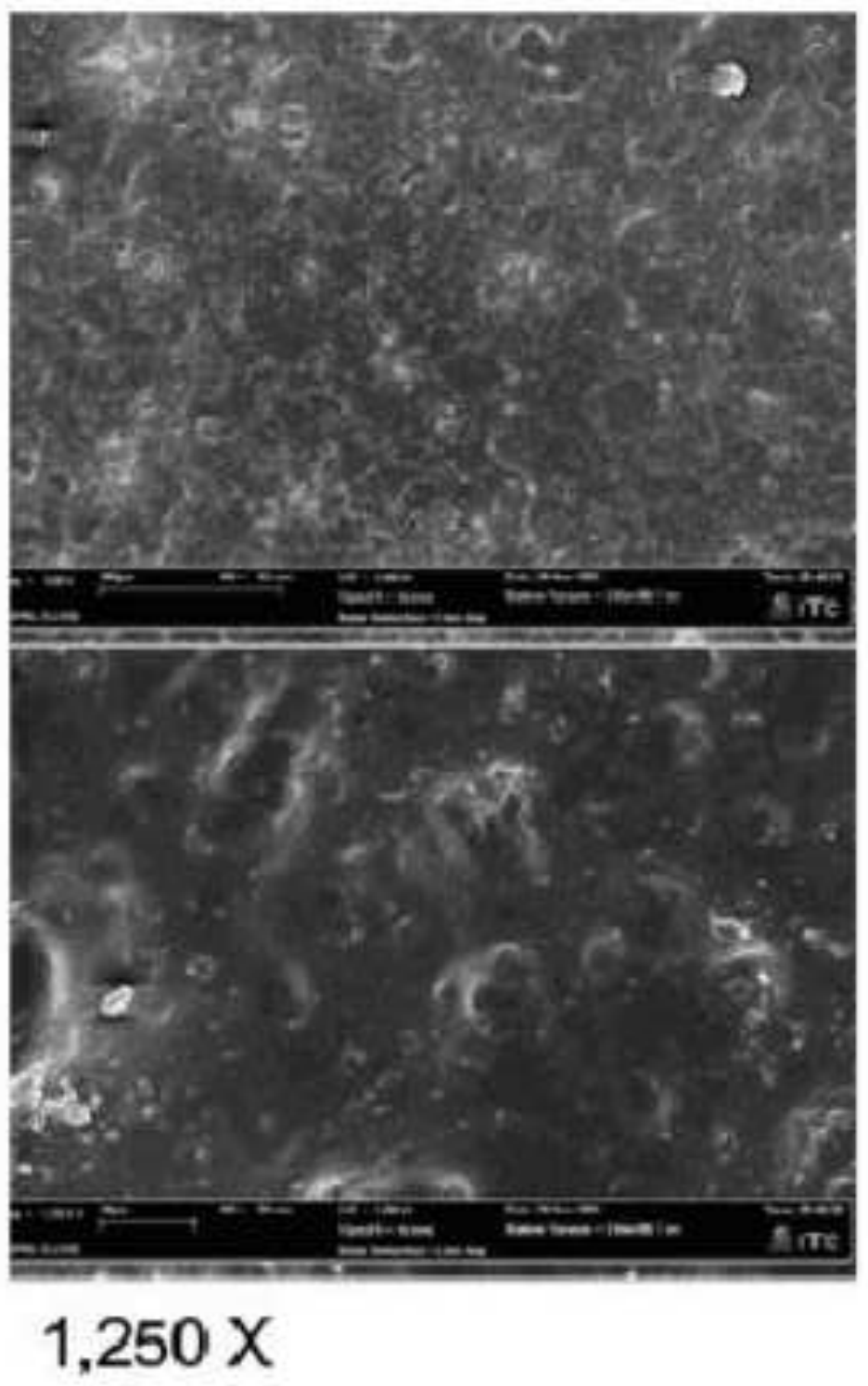

\section{$\sigma^{\circ}$}




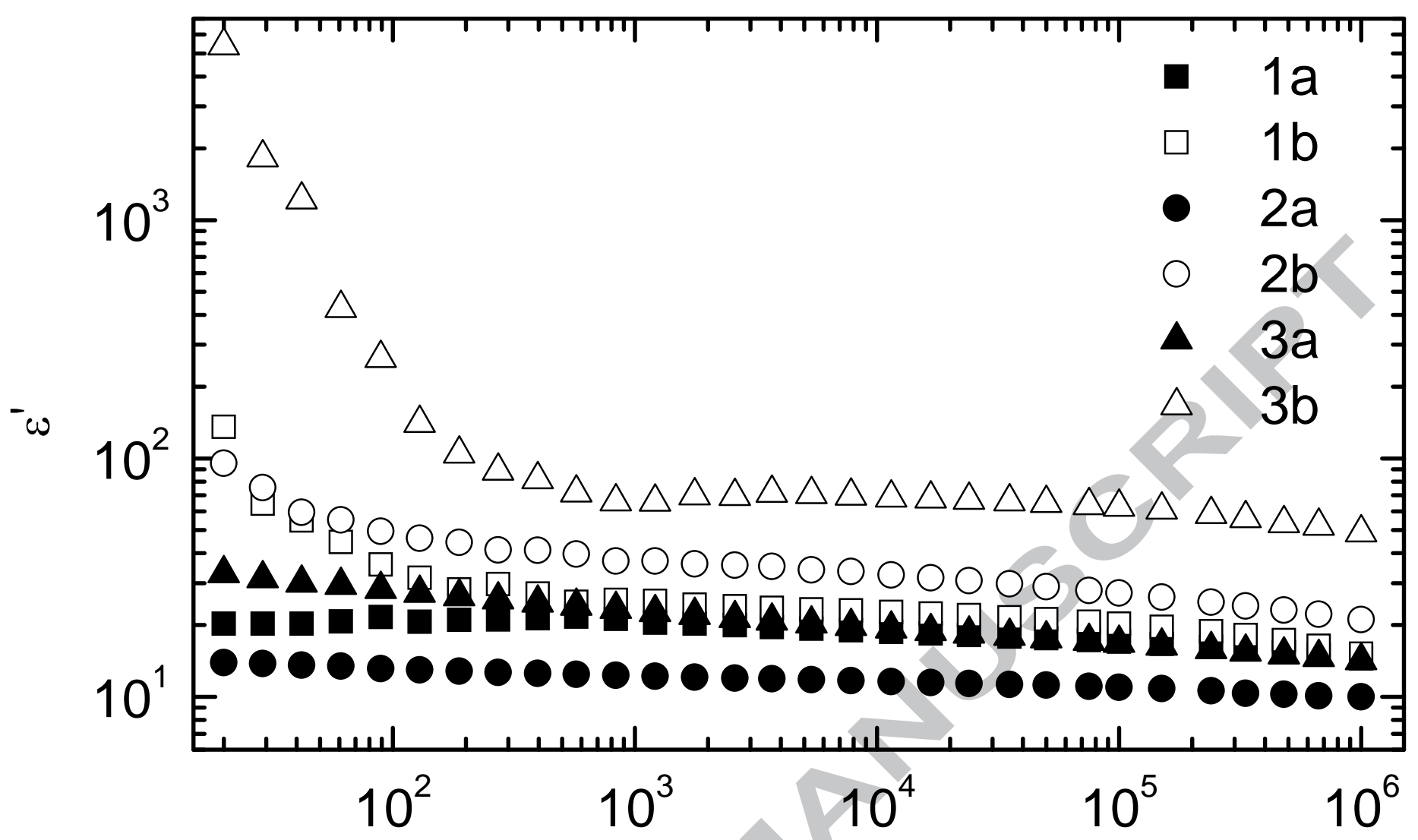

Frequency, $\mathrm{Hz}$

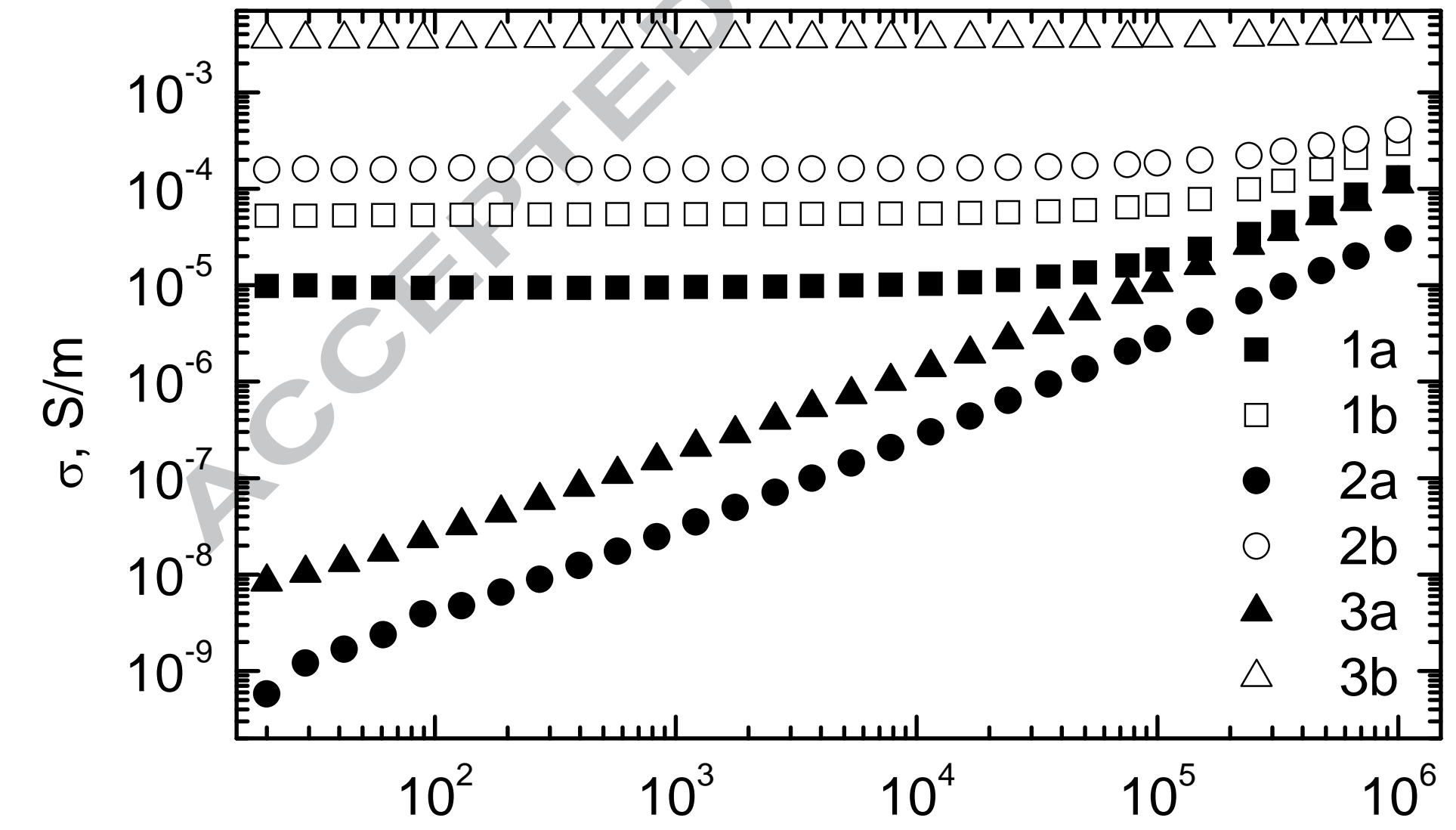

Frequency, $\mathrm{Hz}$ 

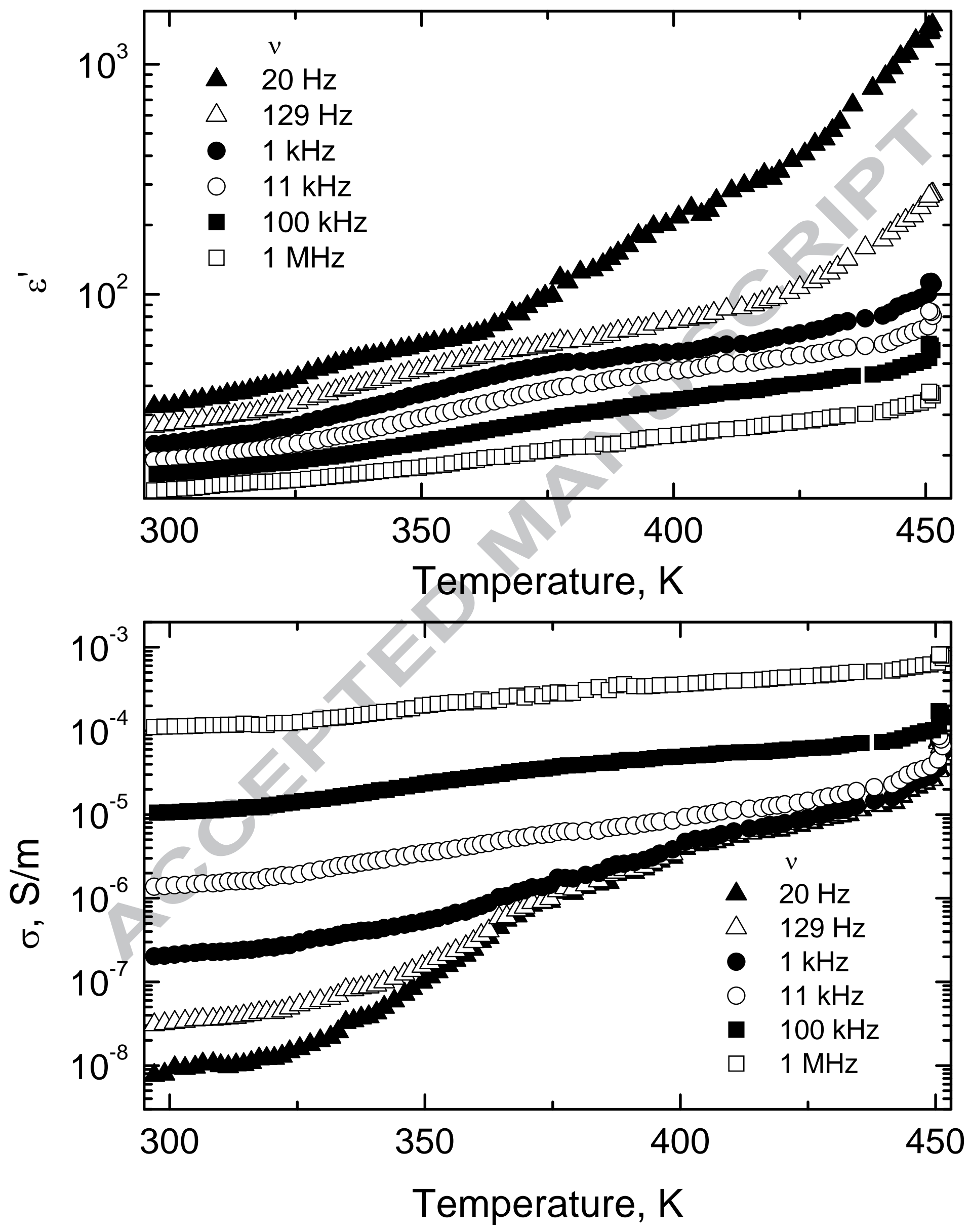


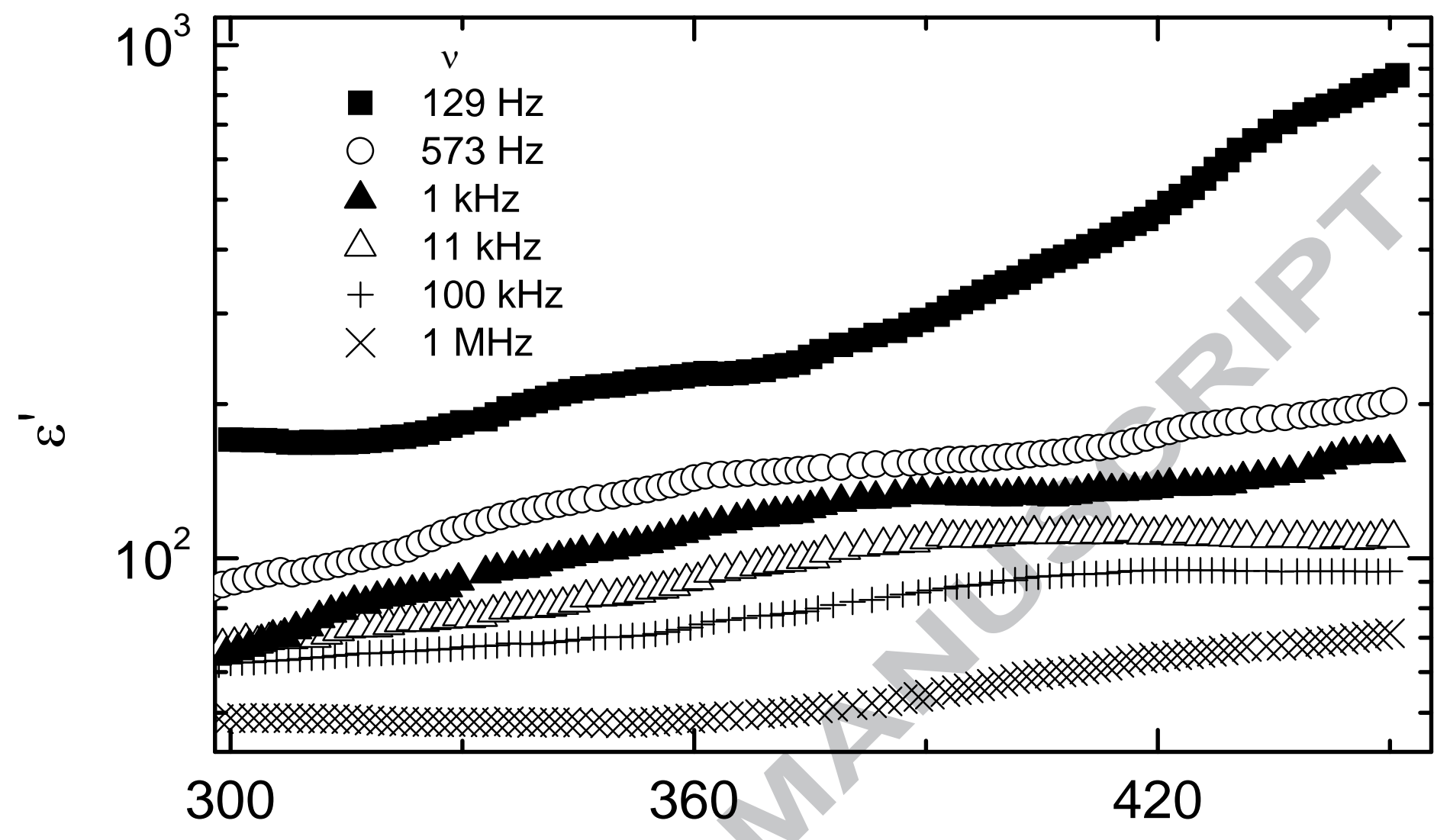

\section{Temperature, $\mathrm{K}$}

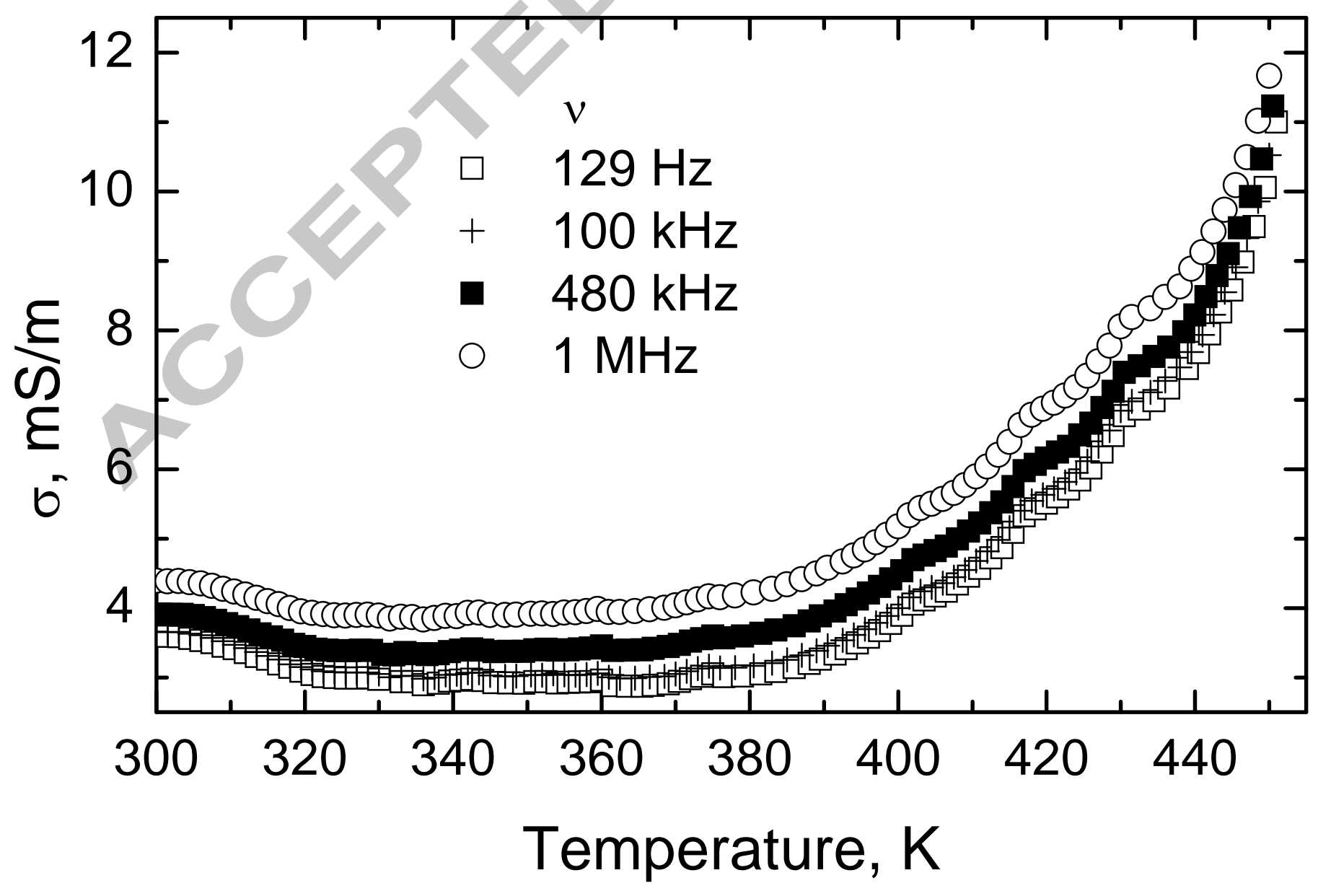




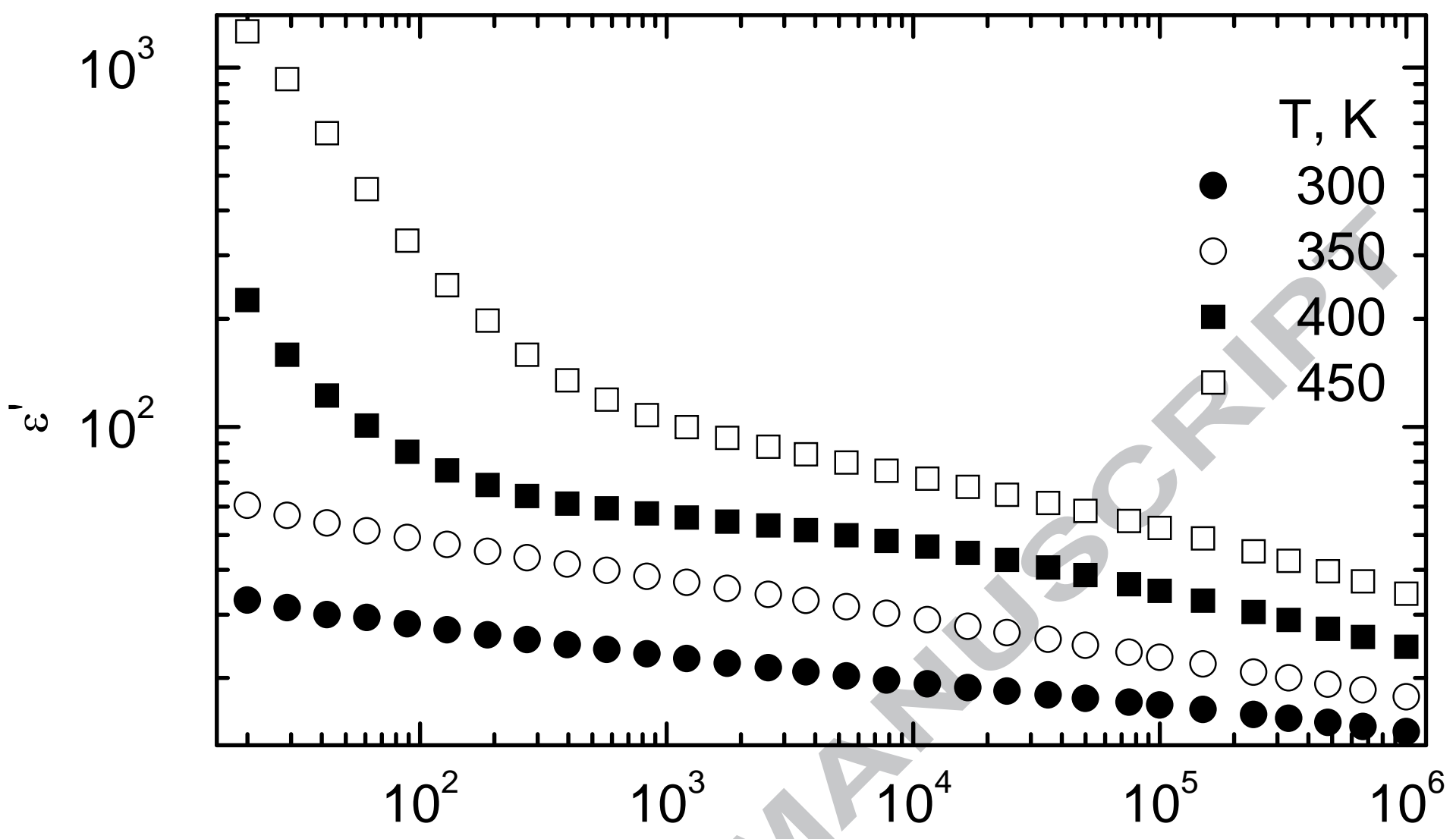

Frequency, $\mathrm{Hz}$

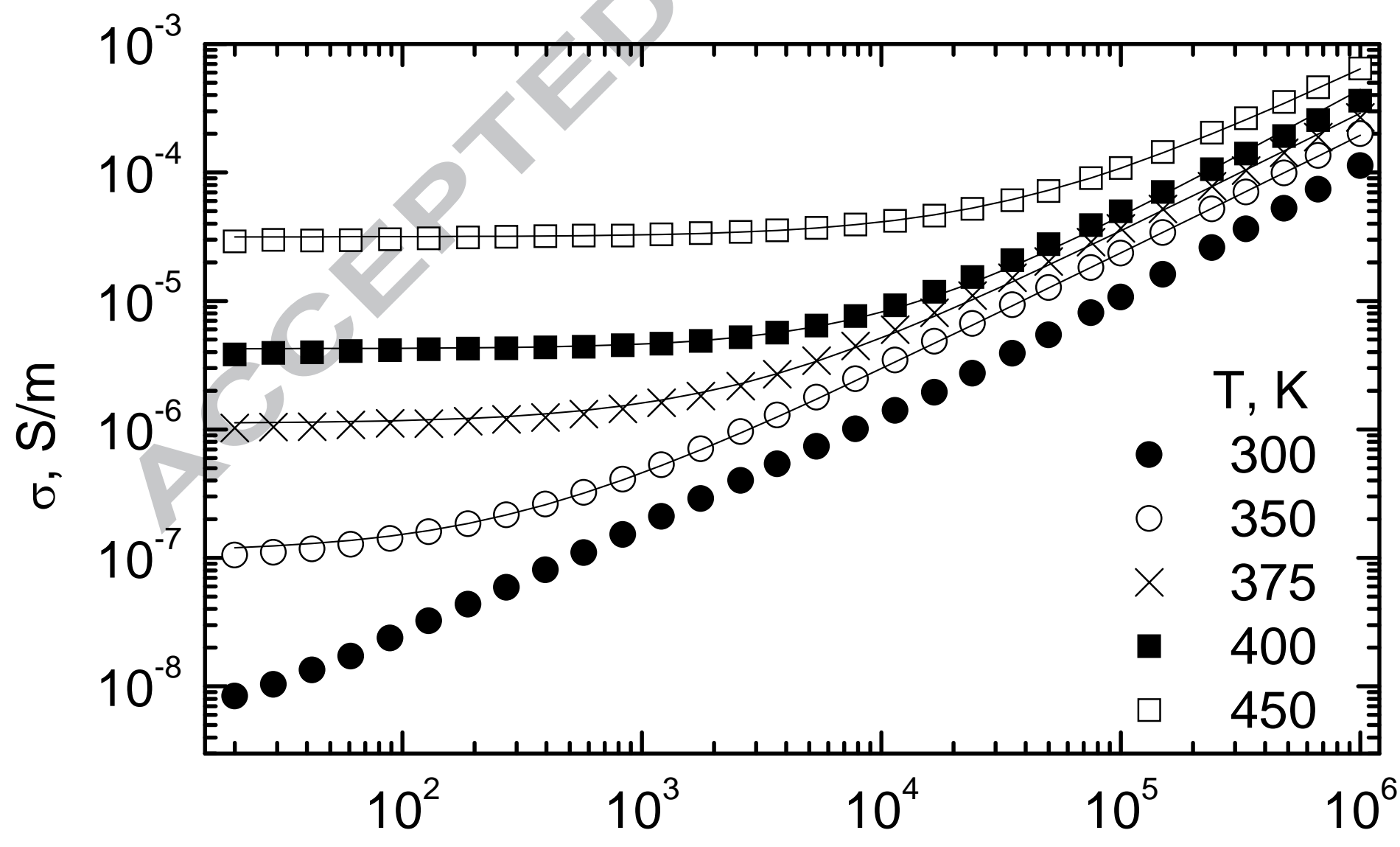

Frequency, $\mathrm{Hz}$ 
$\triangle C C E P T E D$ MANUSCRIPT

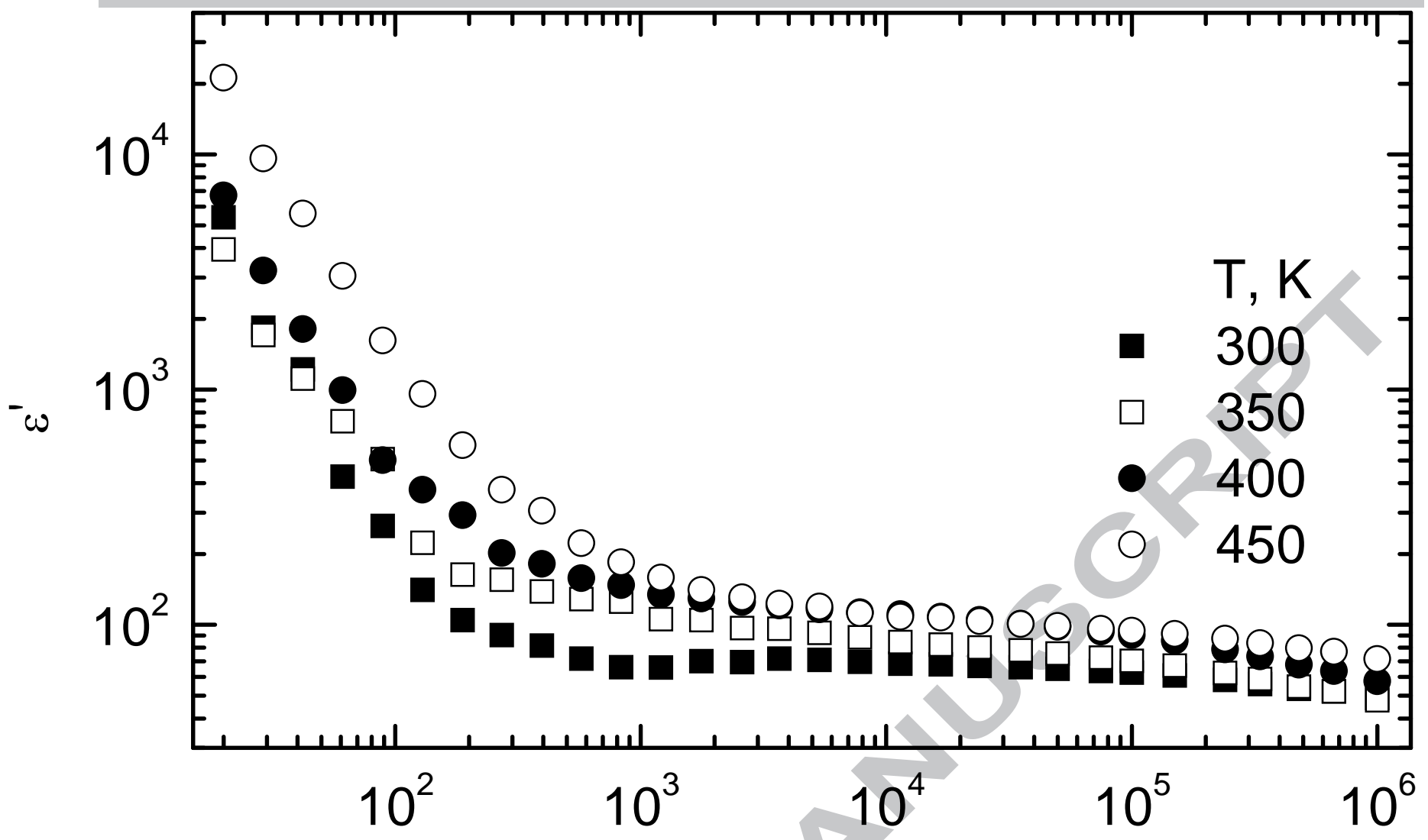

Frequency, $\mathrm{Hz}$

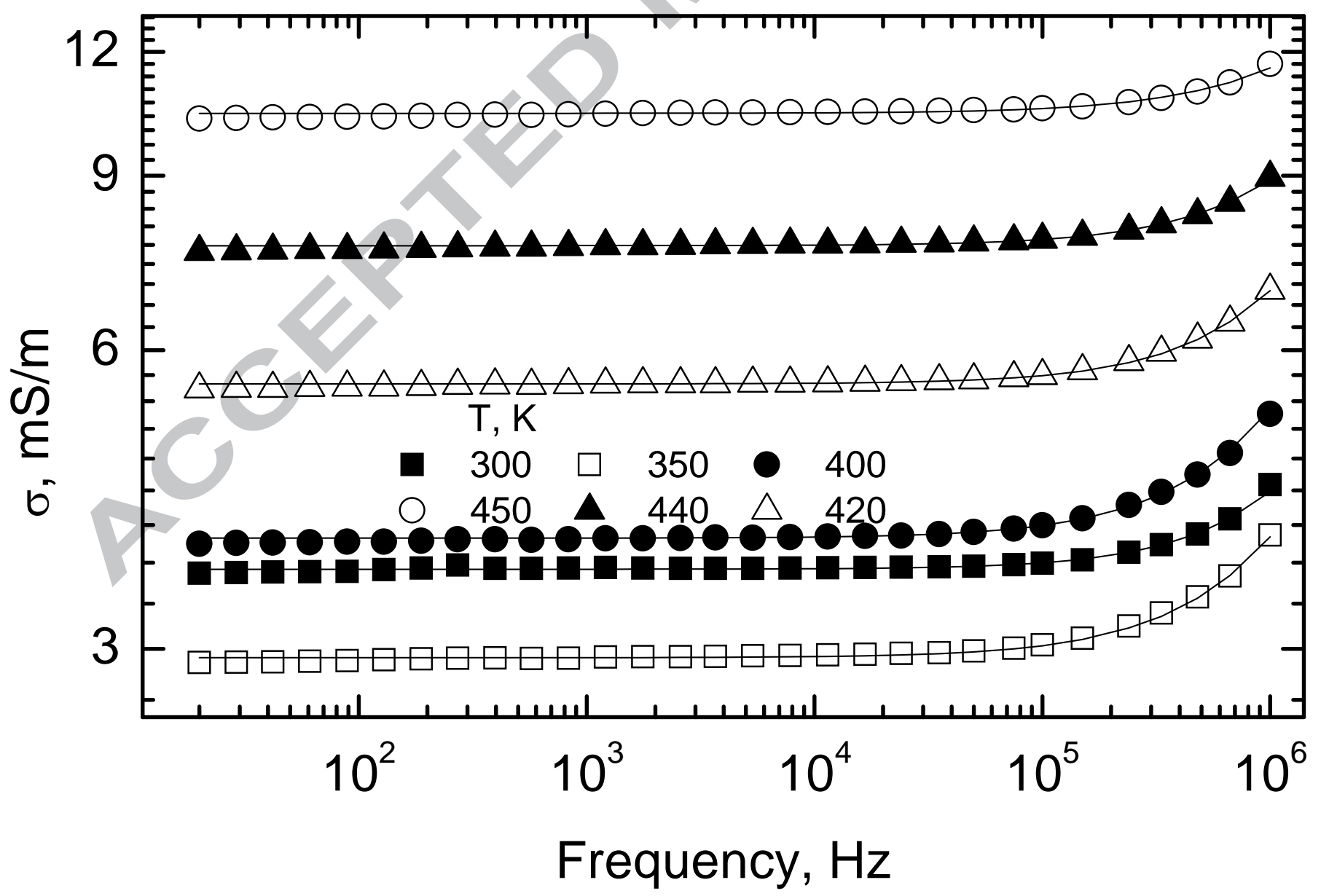



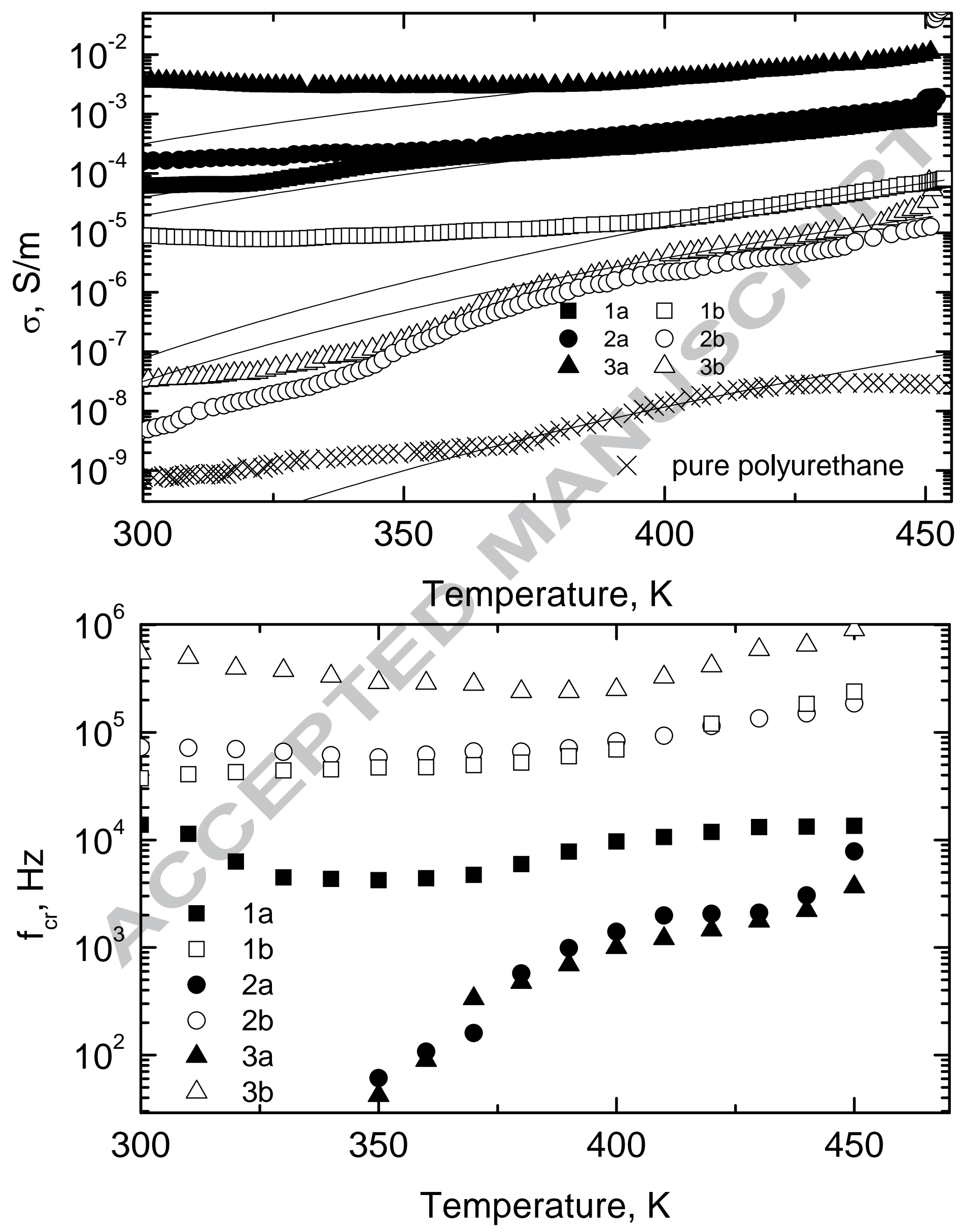

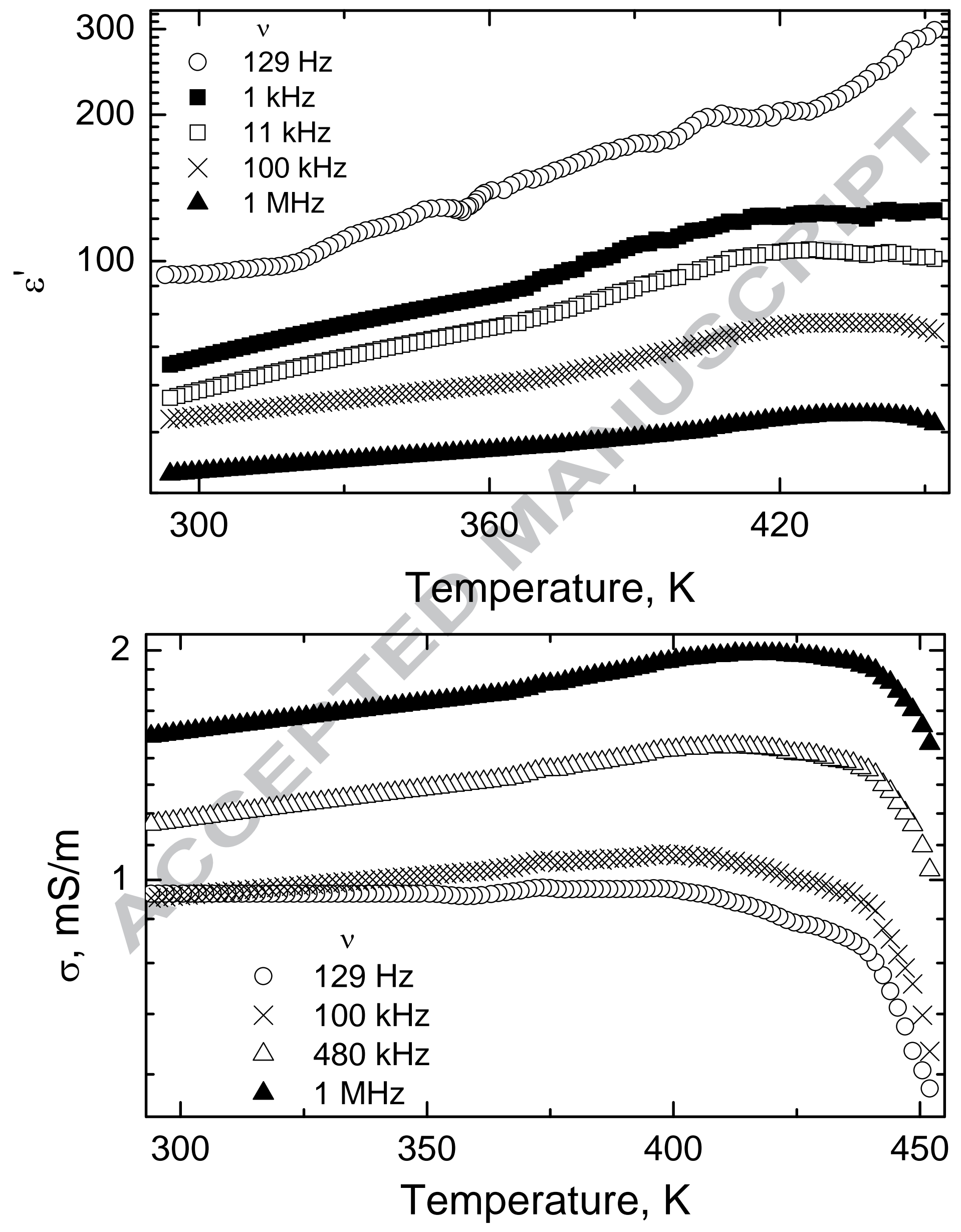

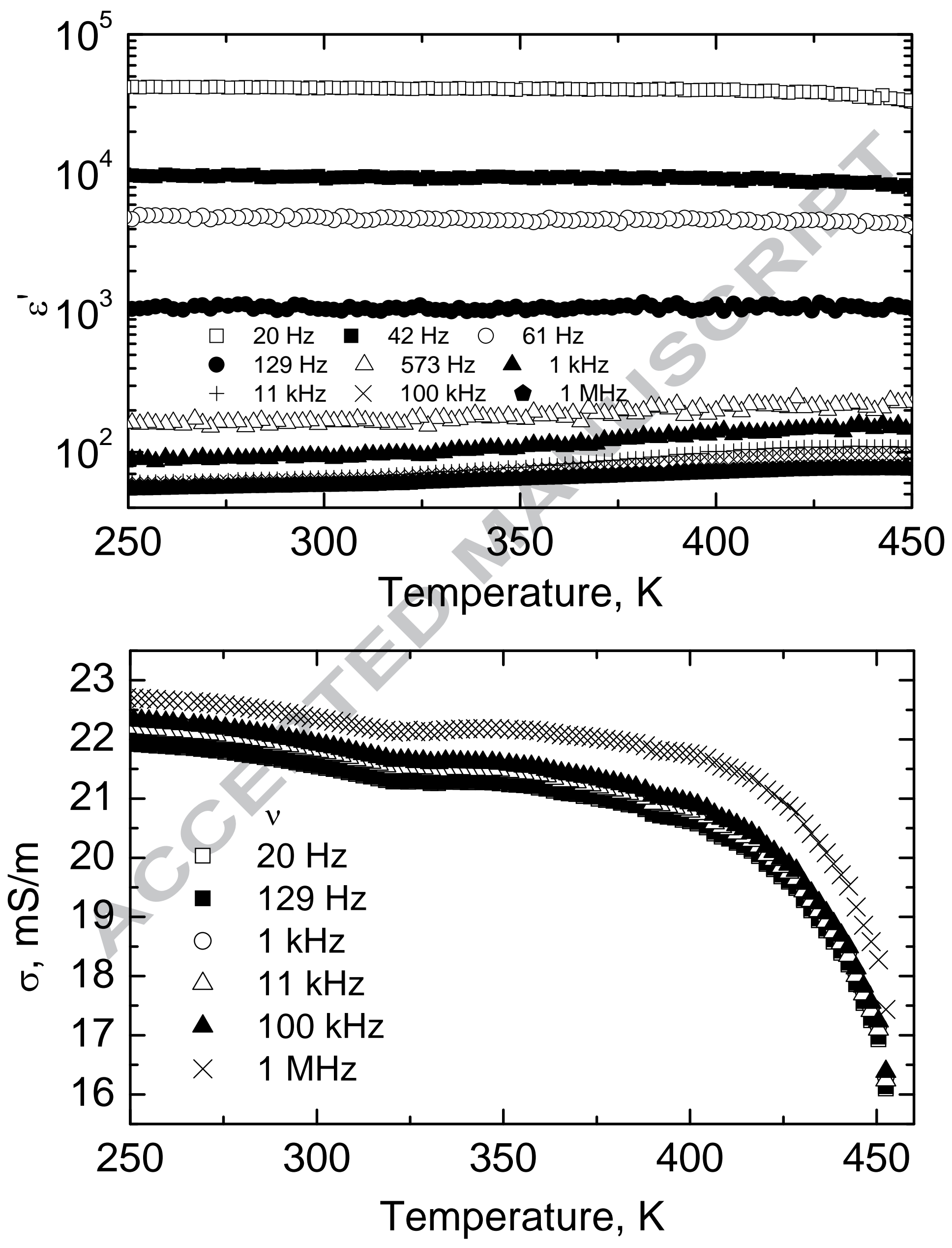

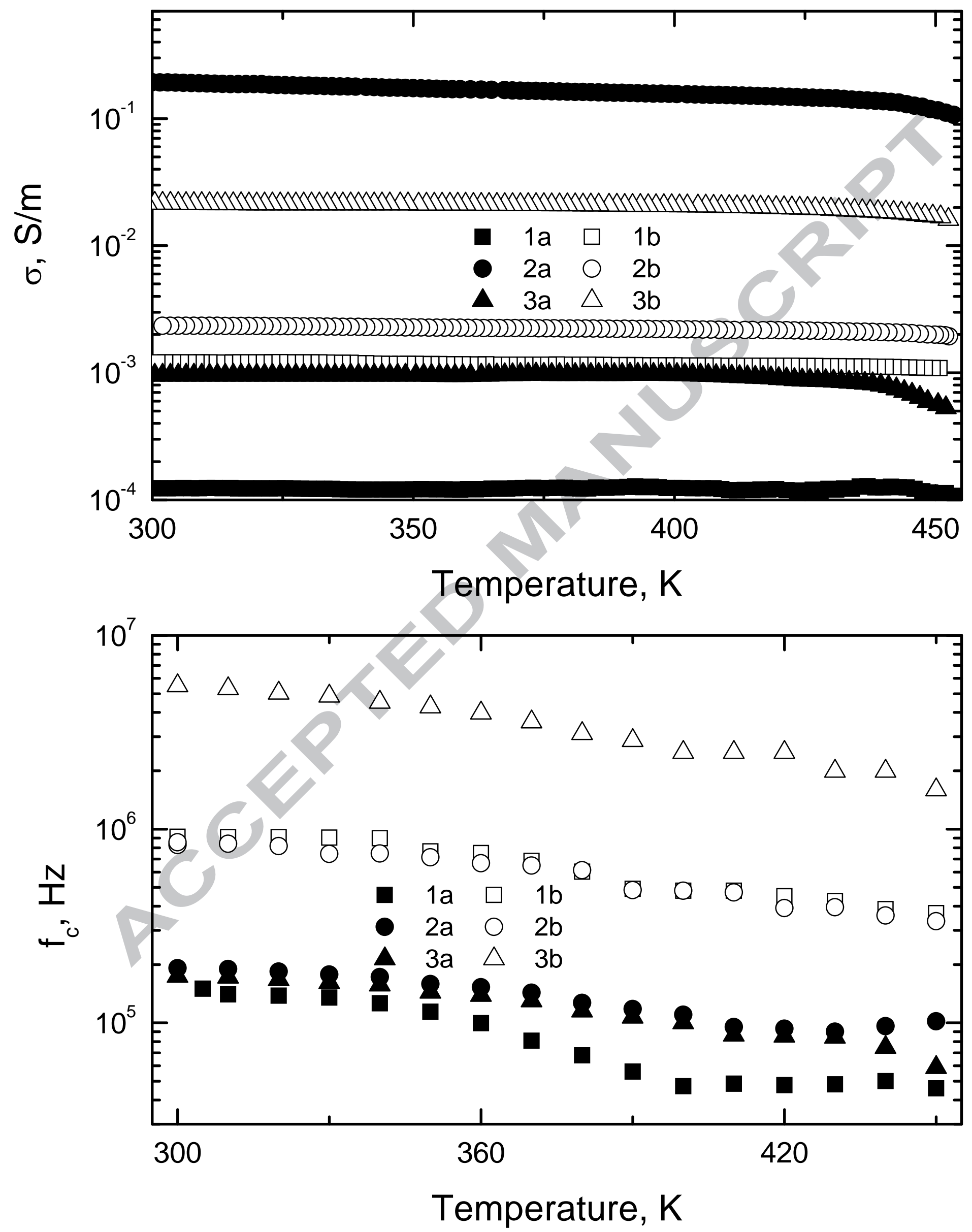